\title{
Characterization of Pseudomonas Mercury-resistance Transposon Tn502, Which Has a Preferred Insertion Site in RP1
}

\author{
By VILMA A. STANISICH ${ }^{1 *}$ R. ARWAS,${ }^{1} \dagger$ P. M. BENNETT ${ }^{2}$ \\ AND F. DE LA CRUZ $\ddagger$ \\ ${ }^{1}$ Department of Microbiology, La Trobe University, Bundoora 3083, Australia \\ 2 Department of Microbiology, Bristol University School of Medical Sciences, \\ Bristol BS8 1TD, UK
}

(Received 12 March 1989; revised 25 July 1989; accepted 11 August 1989)

\begin{abstract}
Tn502mer differs in size and restriction map from the well-characterized Tn501mer. It also differs in its preferential and high-frequency insertion into the $6 \mathrm{~kb}$ Pst I-C region of RP1. The affinity for this region is perpetuated in pVS76, a clone of RP1 Pst I-C in pBR322. Restriction mapping of independent pVS76::Tn502 derivatives revealed that Tn502 inserted at the same site (or small region) in Pst I-C corresponding to the $35 \mathrm{~kb}$ coordinate in RP1. Insertion occurred in both orientations, but one was preferred. When Pst I-C was deleted from RP1, acquisition of Tn502 was reduced and the sites of insertion randomized.
\end{abstract}

\section{INTRODUCTION}

Tn501, originally from Pseudomonas aeruginosa, is the best studied of a group of similarly sized $(7 \cdot 2-8.4 \mathrm{~kb})$ and functionally related transposons that confer resistance only to mercury(II) (Stanisich et al., 1977; Foster, 1987). Tn501 is apparently identical to Tn 1861 (from P. putida; Friello \& Chakrabarty, 1980) and Tn503 (from P. aeruginosa; Arwas, 1982) but differs in restriction map from Tn2613 (from Proteus mirabilis; Tanaka et al., 1983), Tn3926 (from Yersinia enterocolitica; Lett et al., 1985) and the identical pair, Tn3402 and Tn3403 (from Klebsiella and Citrobacter species respectively; Radford et al., 1981 ; Radford, 1984). However, one end of each of Tn2613, Tn3402, Tn3403 and Tn21 (a multi-resistant Tn501-related transposon) is similar, carrying an unusual cluster of three EcoRI and two HindIII sites, and encoding transpositional functions complementary to those of Tn501 (de la Cruz \& Grinsted, 1982; Diver et al., 1983; Tanaka et al., 1983; Radford, 1984). Extensive similarities at the phenotypic and DNA sequence levels also exist between the mer operons of Tn501 and Tn21 (Misra et al., 1984; Gilbert \& Summers, 1988) and to a lesser extent between the mer and transpositional activities of $\operatorname{Tn} 501, \operatorname{Tn} 21$ and $\operatorname{Tn} 3926$ (Lett et al., 1985).

In this paper a new mer transposon, Tn502, is described which differs from $\mathrm{Tn} 501$ in size and restriction map and also in its insertional preference for a site or small region in the Pst I-C region of $\mathrm{RP1}$.

\section{METHODS}

Bacteria and plasmids. The Escherichia coli K12 sub-lines used were UB1301 (prototroph, Rif ${ }^{\mathrm{R}}$ ) (Grinsted et al., 1972), UB1832 (his lys trp $\operatorname{Str}^{\mathrm{R}} \mathrm{Rif}^{\mathrm{R}}$ ) (Sanchez et al., 1982), UB5201 (pro met recA56 Nal ${ }^{\mathrm{R}}$ ) (Sanchez et al., 1982) and its Rif ${ }^{\mathrm{R}}$ derivative, LT105. The Pseudomonas aeruginosa PAO sub-lines used were PAO2003 (argH32

$\dagger$ Present address: Chisholm Institute of Technology, School of Nursing, McMahons Road, Frankston 3199 , Australia.

$\ddagger$ Present address: Departamento de Biología Molecular, Universidad de Cantabria, C. Herrera Oria s/n 39011 Santanda, Spain. 


\section{Table 1. Plasmids used}

Plasmid

Characteristics/comments

Conjugative plasmids

RP1

pUB307

pUB1601

$\mathrm{Ap}^{\mathrm{R}} \mathrm{Tc}^{\mathrm{R}} \mathrm{Km}^{\mathrm{R}}$ IncP

$\mathrm{Tc}^{\mathrm{R}} \mathrm{Km}^{\mathrm{R}}$ IncP; Tn801amp-deletant of RP1

$\mathrm{Tc}^{\mathrm{R}} \mathrm{Km}^{\mathrm{R}}$ IncP; Pst I-ligation derivative; lacks Pst $\mathrm{I}-\mathrm{C}$,

$D, E$ and $F$

R751

pVS991

pVS992

$\mathrm{Tp}^{\mathrm{R}}$ Inc $\mathrm{P}$

R751:: Tn502

pVS993

pUB307tet:: Tn502

pVS6

Non-conjugative plasmids

pBR322

pVS76

pVS982

pUB1601 tet : : Tn502

$\mathrm{Hg}^{\mathrm{R}}$; source of $\mathrm{Tn} 502 \mathrm{mer}$

pVS983

pVS989

pVS994-pVS1001
$A p^{R} T^{R}$

$\mathrm{Tc}^{\mathrm{R}} \mathrm{Ap}^{\mathrm{S}}$ clone of $\mathrm{pBR} 322$; carries RP1 Pst I-C fragment pBR322:: Tn501mer; Tn501 inserted at co-ordinate $2.3 \mathrm{~kb}$ of $\mathrm{pBR} 322$

pBR322tet::Tn502; Tn502 inserted between BamHI

$(0.4 \mathrm{~kb})$ and $S a l \mathrm{I}(0.7 \mathrm{~kb})$ sites of pBR322

pBR322::IS 21 ; IS 21 inserted at co-ordinate $2.5 \mathrm{~kb}$

of pBR322

pVS76::Tn502 derivatives
Source

Grinsted et al. (1972)

Bennett et al. (1977)

Wallace et al. (1981)

Jobanputra \& Datta (1974)

This paper

This paper

This paper

This paper

Bolivar et al. (1977)

Fong \& Stanisich (1989)

This paper

This paper

This paper

This paper

rec-2 $\mathrm{Ch}^{\mathrm{R}} \mathrm{Str}^{\mathrm{R}}$ ) (Chandler \& Krishnapillai, 1974), PAO9503 (met-28 ilv-202 $\mathrm{Str}^{\mathrm{R}}$ ) (Stanisich \& Bennett, 1976) and PAO9501 (pur-136 leu-8 $\mathrm{Chl}^{\mathrm{R}} \mathrm{Rif}^{\mathrm{R}}$ ) (Stanisich \& Ortiz, 1976) together with derivatives of the latter carrying Tn502 inserted between the met-28 and trp-6 chromosomal loci (i.e. PAO9529) or the B3 prophage. The plasmids used are listed in Table 1. pVS6 $\left(\mathrm{Hg}^{\mathrm{R}}, \mathrm{Tra}^{+}\right)$is a new plasmid which confers resistance to mercury(II) but not to organomercurials. It was derived from a $\mathrm{Gm}^{\mathrm{R}} \mathrm{Km}^{\mathrm{R}} \mathrm{Tc}^{\mathrm{R}} \mathrm{Sm}^{\mathrm{R}} \mathrm{Su}^{\mathrm{R}} \mathrm{Hg}^{\mathrm{R}}$ clinical strain of $P$. aeruginosa (provided by R. D. Meyer, Wadsworth Hospital Centre, Los Angeles, California, USA) which transferred only the $\mathbf{H g}^{\mathrm{R}}$ determinant to PAO9501 (frequency $5 \times 10^{-8}$ per donor in a $12 \mathrm{~h}$ broth mating). The pBR322::IS21 derivative was obtained from a rare $A p^{R}\left[S^{2}{ }^{R}\right]$ transconjugant from the cross UB5201(pUB307, pBR322) $\times$ UB1832. Acquisition of IS $2 l$ was confirmed by the plasmid's size (6.5 kb) and the presence of the IS $2 l$-derived $H p a I, K p n I$, SmaI and PstI sites.

Conjugational procedures. (a) Broth matings. These were carried out according to Stanisich \& Bennett (1976). (b) Filter matings. Volumes $(0.5 \mathrm{ml})$ of growing donor and recipient cultures (about $10^{8}$ cells $\mathrm{ml}^{-1}$ ) were filtered through a $25 \mathrm{~mm}$ nitrocellulose membrane $(0.45 \mu \mathrm{m}$ pore size) and the latter placed onto nutrient agar, bacteria uppermost. After incubation $\left(37^{\circ} \mathrm{C}, 1-2 \mathrm{~h}\right)$ the bacteria were resuspended, diluted and plated onto selective medium. (c) Determination of transposition frequency. IncP plasmids were introduced into PAO9529 by conjugation. The transconjugants were isolated and purified once on selective medium, then donor cultures immediately prepared for mating with PAO9503. Selection in the latter mating was for the transposon marker. (d) Determination of conduction frequency. IncP plasmids, with or without a mer transposon, were introduced by conjugation into UB5201 carrying pBR322 or a derivative. Transconjugants and donor cultures derived from them were handled as in (c) except that in matings with UB1832 selection was imposed for a pBR322 marker.

Recombinant DNA procedures. Small-scale and large-scale plasmid preparations, transformation, restriction endonuclease digestion and ligation of DNA, and electrophoresis using agarose $(0.8 \%$ or $1.2 \%)$ or polyacrylamide gels (6\%) were carried out by the standard procedures described in Maniatis et al. (1982).

Abbreviations. Resistance phenotypes are symbolized as follows: Ap, ampicillin; Gm, gentamicin; $\mathrm{Hg}$, mercury(II); Km, kanamycin; Sm, streptomycin; Su, sulphathiazole; Tc, tetracycline; Tp, trimethoprim. The genotype, ter, represents resistance to tellurite.

\section{RESULTS}

\section{Characterization of Tn502}

pVS6 $\left(\mathrm{Hg}^{\mathrm{R}}, \mathrm{Tra}^{+}\right)$does not transfer from P. aeruginosa $\mathrm{PAO}$ to $E$. coli $\mathrm{K} 12\left(<10^{-8}\right.$ per donor). Its carriage of the mercury-resistance transposon, Tn502, was recognized by the recovery of $\mathrm{Hg}^{\mathrm{R}}\left[\mathrm{Rif}^{\mathrm{R}}\right]$ progeny in intergeneric matings between PAO2003(RP1, pVS6) and LT105. These progeny carried RP1::Tn502 derivatives as shown by conjugational linkage analysis and plasmid size. Differences in the insertional specificity of $\operatorname{Tn} 502$ and $\mathrm{Tn} 501$ were suggested by the following observations. (i) Both elements transposed efficiently to RP1 (see next section) but 


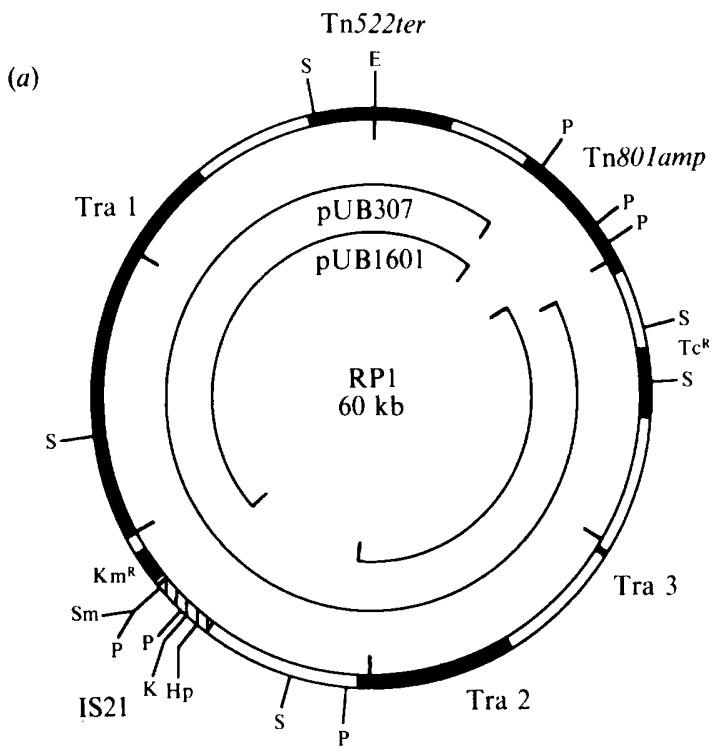

(b)
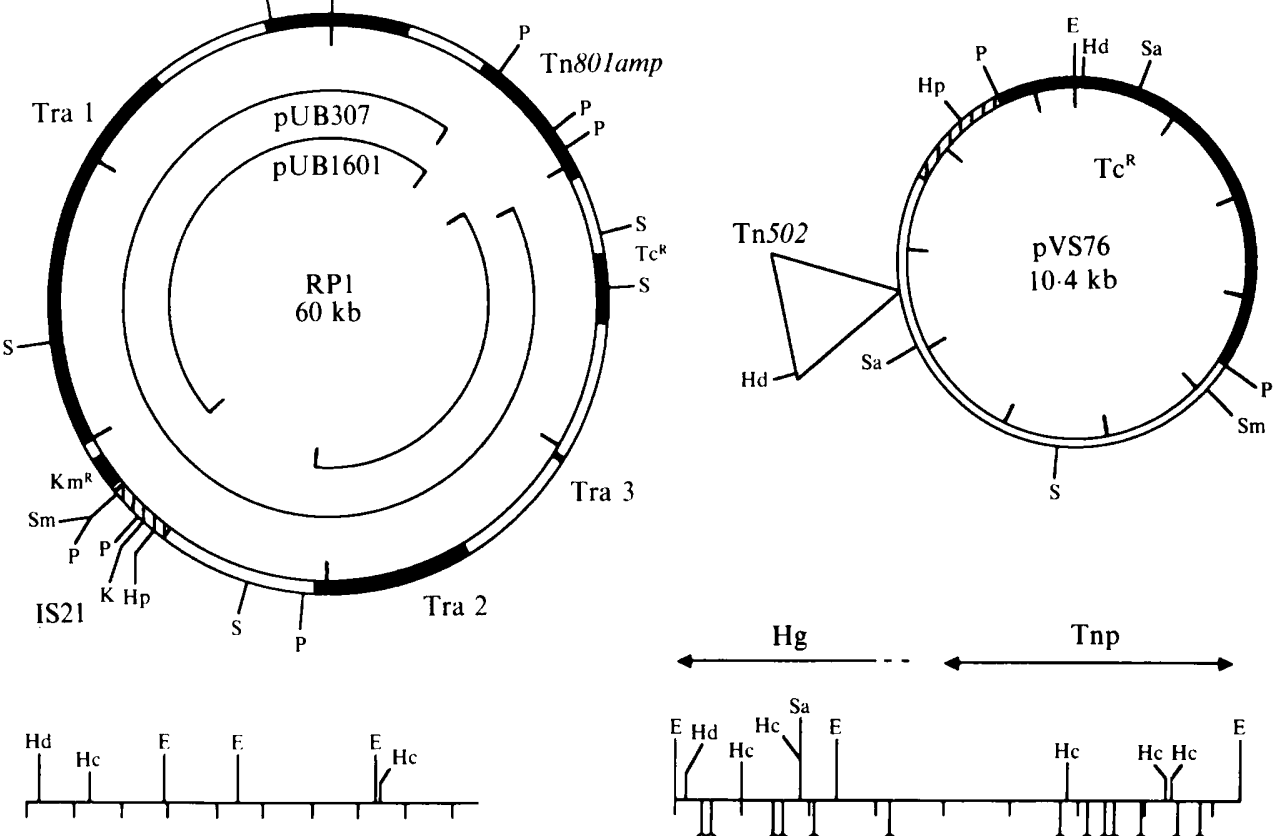

(c)

$\operatorname{Tn} 502(9.6 \mathrm{~kb})$

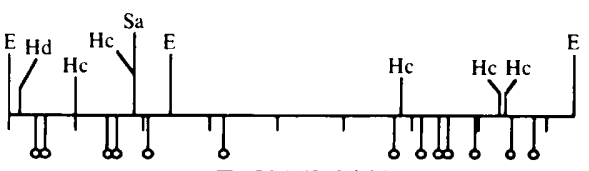

(d)

Tn $501(8.3 \mathrm{~kb})$

Fig. 1. (a) The map of RP1 $(60 \mathrm{~kb})$ (outer circle) is based on that of Thomas \& Smith (1987). The positions of the transfer (Tra) regions, resistance functions and transposable elements (Tn801amp, Tn522ter and IS21) are indicated by the dark and hatched regions. The RP1 derivatives, pUB1601 $(49.2 \mathrm{~kb})$ and pUB307 $(54.8 \mathrm{~kb})$, are represented by the inner circles. pUB1601 is a ligation derivative consisting of the two largest Pst I fragments (Wallace et al., 1981); pUB307 is a Tn801 deletant (Bennett et al., 1977). (b) Plasmid pVS76 (10.4 kb) is a Pst I ligation derivative of pBR322 (dark region) and the $6 \mathrm{~kb}$ Pst I-C fragment of RPI which includes part of IS21 (hatched region). The preferred site of insertion of Tn502 in Pst I-C and the preferred orientation of Tn502 are indicated by the triangle. (c) The map of Tn $502 m e r(9.6 \mathrm{~kb})$. (d) The map of Tn50Imer $(8.3 \mathrm{~kb})$ is based on that of Bennett $e$ al. (1978) and Lett et al. (1985) and shows the regions responsible for mercury-resistance $(\mathrm{Hg})$ and transpositional activity (Tnp). The location of BglI sites is shown below the map by the open-circle symbols. These occur at the following kb map locations: $0 \cdot 42,0 \cdot 51,1 \cdot 49,1 \cdot 65,2 \cdot 05,3 \cdot 20,5 \cdot 78,6 \cdot 17,6 \cdot 41$, $6 \cdot 57,6 \cdot 95,7 \cdot 47,7.88$ and are taken from the Tn501 nucleotide sequence of Brown et al. $(1983,1985$, 1986 ) and Lund et al. (1986). In all figures cleavage sites for various restriction enzymes are as follows: EcoRI (E), HincII (Hc), HindIII (Hd), HpaI (Hp), KpnI (K), PstI (P), SalI (Sa), SmaI (Sm), SstII (S). The location of only one of the four KpnI sites of RPl is shown.

Tn502 failed to inactivate any of the $R P 1$ resistance functions $\left(\operatorname{Ap}^{R} \mathrm{Km}^{R} \mathrm{Tc}^{\mathrm{R}}\right)(<0.05 \%)$ under conditions that yielded insertional mutants with Tn501 (0.2-2\%; Stanisich et al., 1977). (ii) Previous studies showed that in matings between $\mathrm{RP} 1^{+}$donors and $\mathrm{B} 3$-lysogenic recipients the transconjugants inherited plasmids with deletions of the $\mathrm{Km}^{\mathrm{R}}$ or (some) tra loci (Stanisich \& Bennett, 1976). When six independent RP1::Tn502 plasmids were subjected to deletion formation, mer was lost together with the Tra and/or $\mathrm{Km}^{\mathrm{R}}$ functions in $10-42 \%$ of the transconjugants. This suggested that $\mathrm{Tn} 502$ occurred in the Tra $1-\mathrm{Km}^{\mathrm{R}}-\mathrm{Tra} 2$ region (Fig. $1 a$ ) of all six plasmids but at a site(s) that did not affect either $\mathrm{Tra}$ or $\mathrm{Km}^{\mathrm{R}}$ activities. A corresponding loss of mer was not found when three RP1::Tn501 plasmids were similarly tested. (iii) Conduction of pBR322 (a non-conjugative mobilization-deficient plasmid; Finnegan $\&$ Sherratt, 1982) was mediated efficiently by $\mathrm{Tn} 501$ but not by $\mathrm{Tn} 502$ (i.e. frequencies of $3 \times 10^{-5}$ and $2 \times 10^{-8}$ from the respective pUB307:: $\mathrm{Tn}^{+} \mathrm{pBR} 322^{+}$donors).

A pBR322-Tn plasmid from each conductional experiment from (iii) above was used to compare the molecular features of the two transposons. Tn 502 was larger than Tn 501 (9.6 kb vs 
$8.3 \mathrm{~kb}$ ) and differed in the number and distribution of EcoRI, HincII and SalI sites (Fig. 1c,d) although both carried a HindIII site at one end. Further disparity in the molecular structure of these transposons was evident from $B g l$ I digests subjected to polyacrylamide gel electrophoresis (data not shown). pBR322::Tn501 produced 11 bands, of which five were doublets as deduced from the Tn501 Bgll map (Fig. $1 d$ ); pBR322::Tn502 produced 17 bands including one possible doublet. Whilst the positions of the Tn502 BglI sites were not determined, the 14 internal transposon fragments could be identified and compared with the 12 from Tn501. Only two of these, of $90 \mathrm{bp}$ and $160 \mathrm{bp}$, were of similar mobility. Thus at the gross level reflected by these various genetic and molecular tests, Tn 501 and $\mathrm{Tn} 502$ are clearly distinguishable. Tn 502 also bears no obvious similarity to other mer transposons for which sizes and molecular maps have been reported.

\section{Transposition of Tn502 to RP1 and derivative plasmids}

Information regarding the insertional specificity of Tn 502 in RP1 was obtained by comparing its transposition frequency to RP1 and the derivative plasmids pUB307 and pUB1601. The latter two have sustained deletions involving the four small Pst I fragments (Fig. 1 $a$ ). When each plasmid was passaged through PAO9529, which carries a chromosomal Tn502, transposition to RP1 and pUB307 occurred at frequencies of about $3 \times 10^{-3}$ per donor, compared to a significantly reduced frequency to pUB 1601 of $10^{-6}$ per donor. This suggests that loss of the $6.0 \mathrm{~kb}$ Pst $\mathrm{I}-\mathrm{C}$ and/or the adjacent $0.8 \mathrm{~kb}$ Pst $\mathrm{I}-\mathrm{E}$ fragment of $\mathrm{RP} 1$, which occur in the $\mathrm{Km}^{\mathrm{R}}-\mathrm{Tra} 2$ region, leads to reduced acquisition of $\mathrm{Tn} 502$.

The location of Tn502 in eight RP1::Tn502 and six pUB307::Tn502 derivatives was determined by comparing their PstI profiles with those of the parent plasmids. In all cases, Tn502 (which has no Pst I sites) occurred in the Pst I-C fragment. Since the Tn $502^{+}$plasmids had originated from three transpositional donors (i.e. pVS6, pVS983 and PAO9529) including Rec ${ }^{+}$ and $\mathrm{Rec}^{-}$lines, it appears that $\mathrm{Tn} 502$ has a strong insertional preference for the Pst I-C region. In pUB1601, where the Pst I-C region is absent, acquisition of Tn 502 was reduced and the sites of insertion random. This was suggested by the isolation of $\mathrm{Tc}^{\mathrm{s}}$ mutants $(6 / 150$ tested) (but no $\mathrm{Km}^{\mathrm{S}}$ or $\mathrm{Tra}^{-}$mutants), and the location of Tn502 in three pUB1601 ::Tn502 plasmids tested. In $P s t \mathrm{I} /$ Sst II digestions of these, Tn502 (which lacks Pst I or Sst II sites), occurred in the $1.8 \mathrm{~kb}$ Sst II fragment of the tet gene in a mutant with a $\mathrm{Tc}^{\mathrm{S}}$ phenotype, and in the $3.4 \mathrm{~kb}$ or $16.3 \mathrm{~kb}$ Pst I/Sst II fragments adjacent to the tet gene in two plasmids with unaltered RP1-phenotypes (Fig. 1a) (data not shown).

\section{Tn502-mediated conduction of $p B R 322$ and its derivatives}

Tn502-mediated conduction of pBR322 occurs only rarely (data presented above). This feature provided a system for the further analysis of $\mathrm{Tn} 502$ behaviour in terms of its affinity for Pst I-C and the possible role of IS21 in this interaction given that part of it occurs at one end of Pst I-C (Fig. 1 a). The ability of pBR322 and two derivatives, pBR322-Pst I-C (i.e. pVS76; Fong \& Stanisich, 1989) and pBR322::IS21 (see Methods), to be transferred via cointegrate formation with various resident $\mathrm{Tn} 502^{+}$conjugative plasmids was then assessed in a $\mathrm{Rec}^{-}$host. Efficient conduction occurred only with the pBR322-Pst I-C derivative (Table 2). Thus relocation to pBR322 of Pst I-C DNA, but not of IS21, markedly enhances the interaction of this plasmid with Tn502.

\section{Tn502 site-specificity in PstI-C DNA}

In order to determine the specificity of insertion of $\mathrm{Tn} 502$ in the Pst $\mathrm{I}-\mathrm{C}$ region, eight pVS76::Tn502 derivatives, obtained by conduction from independently constructed pUB1601tet:: $\operatorname{Tn} 502^{+}$pVS76 ${ }^{+}$donors and recovered by transformation, were analysed. All eight were larger than pVS76 by about $10 \mathrm{~kb}$ (the approximate size of Tn502) and had insertions in the Pst I-C DNA. These insertions were all in the smaller $2.6 \mathrm{~kb}$ Sal I-Pst I segment and, in seven cases, the orientation of insertion was the same (i.e. with the HindIII end of Tn 502 nearest the SalI site in Pst I-C). The site of Tn502 insertion was also apparently identical and was 
Table 2. Tn502-mediated conduction of pBR322 and its derivatives

\author{
Mobilizing \\ plasmid \\ pUB307tet:: Tn 502 \\ pUB1601 tet : : Tn502 \\ R751::Tn502
}

Transfer frequency* of :

\begin{tabular}{rcc}
\multicolumn{1}{c}{ pBR322 } & pBR322::IS21 & pBR322-PstI-C \\
$<2.0 \times 10^{-8}$ & $<2.0 \times 10^{-8}$ & $1.6 \times 10^{-2}$ \\
$2.2 \times 10^{-7}$ & $8.6 \times 10^{-7}$ & $2.5 \times 10^{-3}$ \\
$<2.0 \times 10^{-8}$ & $4.0 \times 10^{-7}$ & $8.0 \times 10^{-3}$
\end{tabular}

\begin{abstract}
* Donors were UB5201 sub-lines carrying an IncP plasmid and either pBR322 or a derivative of it. The recipient was $U B 1301$. Filter-matings were carried out and $T p^{R}\left[\operatorname{Rif}^{R}\right]$ or $\operatorname{Km}^{\mathrm{R}}\left[\operatorname{Rif}^{\mathrm{R}}\right]$ transconjugants selected to determine the transfer frequency of the R751 derivative and the RP1-deletant plasmids respectively. In all cases the transfer frequency was $0 \cdot 4-0 \cdot 8$. Conductional transfer of pBR322 or its derivatives was determined from the number of $\mathrm{Tc}^{\circledR}\left[\mathrm{Rif}^{\circledR}\right]$ transconjugants. Control experiments in which pUB307, pUB1601 and R751 were used yielded low or no $\left(<5 \times 10^{-7}\right)$ conductional transfer of $\mathrm{pBR} 322$ or its derivatives as determined from the recovery of $A p{ }^{\circledR}\left[\mathrm{Rif}^{\circledR}\right]$ transconjugants.
\end{abstract}

determined precisely from SalI/HindIII digests. In all cases these generated a $0.7 \mathrm{~kb}$ Pst I-C-Tn 502 junction fragment. Since HindIII occurs $0.2 \mathrm{~kb}$ from the Tn 502 terminus, the transposon insertion site must be $0.5 \mathrm{~kb}$ from the $\mathrm{Sal}$ I site (Fig. $1 b$ ). Tn 502 was also inserted in the same site in the remaining plasmid, although in the opposite orientation. In this case junction fragments of $2.2 \mathrm{~kb}$ and $1.8 \mathrm{~kb}$ were found in $\mathrm{HindIII} / \mathrm{Pst} \mathrm{I}$ and $\mathrm{HindIII} / \mathrm{HpaI}$ digestions respectively. Thus, Tn 502 insertions into the $2.6 \mathrm{~kb}$ Pst I-Sal I segment of the Pst I-C fragment are not randomly distributed but occur in a preferred orientation and at a site or small region $0.5-0.6 \mathrm{~kb}$ from the SalI end. This site corresponds to co-ordinate $35 \mathrm{~kb}$ in RP1.

\title{
DISCUSSION
}

In this study, genetic and molecular differences between the $P$. aeruginosa mer transposons, Tn 501 and Tn502, have been identified. Both elements transpose efficiently to RP1 but differ in their target specificity. Grinsted et al. (1978) have shown that Tn501 insertions occur at many sites flanking the Tn801amp element but rarely (about $5 \%$ of events) in the $\mathrm{Km}^{\mathrm{R}}$-Tra region. The latter observation is consistent with our finding that deletions in RP1 ::Tn 501 plasmids that involved the $\mathrm{Km}^{\mathrm{R}}$ region did not affect mer. In contrast, the Pst $\mathrm{I}-\mathrm{C}$ fragment of this region or, more precisely, a site within it, is strongly preferred by Tn502. This was shown by: (i) the co-deletion of mer with Tra and/or $\mathrm{Km}^{\mathrm{R}}$ functions in RP1 : :Tn 502 plasmids; (ii) the low affinity of Tn502 for pUB1601 compared to RP1 and pUB307; (iii) the ability of Tn502+ conjugative plasmids to mobilize a pBR322-Pst I-C construct but not pBR322 or an IS21 $1^{+}$derivative; and (iv) the mapping of a target site at the $35 \mathrm{~kb}$ co-ordinate of RP1.

The observation that IS 21 did not enhance the affinity of Tn 502 for pBR322 was significant since the right end of IS 21 is part of the Pst I-C DNA. It was possible, therefore, that this end of IS21 'directed' transposition of Tn502 into the Pst I-C DNA. Such a situation occurs with Tn7, where nucleotides some $12 \mathrm{bp}$ from the target site, but not within it, influence transposition to the $E$. coli $\mathrm{K} 12$ chromosome (Gringauz et al., 1988). 'Directed' transposition by IS21 acting alone has been excluded as a possibility and was probably an unlikely one given the $1 \mathrm{~kb}$ distance between the IS 21 terminus and the Tn 502 target site. The extreme site-specificity of $\mathrm{Tn} 7$ for the $E$. coli $\mathrm{K} 12$ chromosome or of IS 2 for $\lambda$ is accompanied by total orientational specificity (Saint-Girons et al., 1981; Gringauz et al., 1988). This does not occur with Tn502 although one orientation is preferred (1:7 in pVS76) compared to that found with Tn501 (about $1: 1$ for RP1 and 1:2 for pUB307; Grinsted et al., 1978).

Only two functions (mrs, Thomas \& Smith, 1987; and fiwA, Fong \& Stanisich, 1989) have been ascribed to the Pst I-C region of RP1 and none is known involving the Tn 502 target site. This site may also be favoured by the $P$. aeruginosa transposon $\operatorname{Tn} 2521\left(\mathrm{Cb}^{\mathrm{R}} \mathrm{Sm}^{\mathrm{R}} / \mathrm{Sp}^{\mathrm{R}} \mathrm{Su}^{\mathrm{R}}\right.$; $6.8 \mathrm{~kb}$ ), which inserts $0.6 \mathrm{~kb}$ distal to the SalI site in Pst I-C (Sinclair \& Holloway, 1982). Insertions of $\operatorname{Tn} 2521$ occurred in one orientation, but as only four events were studied this difference to Tn502 may not be significant. However, these elements differ in three further respects: (i) Tn2521 does not transpose in a $\mathrm{Rec}^{-}$host; (ii) the affinity of $\operatorname{Tn} 2521$ for $\mathrm{R} 18$ 
(a plasmid identical to RP1; Thomas \& Smith, 1987) is low $\left(10^{-6}\right)$ compared to that of Tn502 $\left(10^{-3}\right)$; and (iii) the chromosomal location of Tn2521 in P. aeruginosa clinical isolates is confined to a site or region co-transducible with the $P$. aeruginosa PAO pur-136 locus (map position $25 \mathrm{~min}$ ) (Sinclair \& Holloway, 1982). Of two Tn502 chromosomal insertions studied in strain PAO, one occurred between the met- $28(31 \mathrm{~min})$ and trp-6 $(28 \mathrm{~min})$ loci, as deduced from chromosome mobilization data, and the other between $\arg B$ and $p y r E$ (both about $19 \mathrm{~min}$ ) and co-transducible with these loci (Arwas, 1982). The single feature of similarity between Tn 502 and Tn2521 may thus be their preference for the same site or small region in RP1.

Our molecular comparisons of $\mathrm{Tn} 501$ and $\mathrm{Tn} 502$ were limited to an examination of their restriction maps and $B g l \mathrm{I}$ profiles. The latter, in particular, did not identify strong similarities with Tn501 either in the $\operatorname{tnp} A$ region, which generates six $B g l \mathrm{I}$ fragments, or the mer region, which generates five. Differences in the target specificities of Tn501 and Tn502 for RP1 and pBR322 could, therefore, be due to different $\operatorname{tnp} A$ activities. The mercuric reductases specified by $\mathrm{Tn} 501$ and $\mathrm{Tn} 502$ are also known to be different. Such reductases from different Gramnegative bacteria are immunologically related but comprise two sub-classes - a type I enzyme is specified by Tn 501 and a type II enzyme by Tn 502 (Silver, 1983; Foster, 1987). Thus, at the gross level, Tn502 appears to differ in both genetic and molecular features from the small group of transposons that encode single resistance to mercury(II) and are all related to Tn501.

Financial support for this work was provided by the Australian Research Grants Scheme (to V.A.S.) and the Science and Engineering Research Council (UK) (to P.M.B.). R.A. was the recipient of an Australian Commonwealth Post-graduate Research Award.

\section{REFERE NCES}

ARWAS, R. (1982). A study of transposons and transposon-mediated genetic interactions in Pseudomonas aeruginosa. $\mathrm{PhD}$ thesis, $\mathrm{La}$ Trobe University, Australia.

Bennett, P. M., Grinsted, J. \& Richmond, M. H. (1977). Transposition of TnA does not generate deletions. Molecular and General Genetics 154, 205-211.

BennetT, P. M., Grinsted, J., ChOI, C. L. \& RICHMOND, M. H. (1978). Characterisation of Tn501, a transposon determining resistance to mercuric ions. Molecular and General Genetics 159, 101-106.

Bolivar, F., Rodriguez, R. L., Green, P. J., Betlach, M. C., Heyneker, H. L., Boyer, H. W., Crosa, J. H. \& FALKow, S. (1977). Construction and characterizaton of new cloning vehicles. II. A multipurpose cloning system. Gene 2, 95-113.

Brown, N. L., Ford, S. J., Pridmore, D. \& FRITZINGER, D. C. (1983). Nucleotide sequence of a gene from the Pseudomonas transposon Tn501 encoding mercuric reductase. Biochemistry 22, 4089-4095.

Brown, N. L., Winnie, J. N., Fritzinger, D. \& PRIDMORE, R. D. (1985). The nucleotide sequence of the tnpA gene completes the sequence of the Pseudomonas transposon Tn501. Nucleic Acids Research 13, 5657-5669.

Brown, N. L., Misra, T. K., Winnie, J. N, Schmidt, A., SeIfF, M. \& Silver, S. (1986). The nucleotide sequence of the mercuric resistance operons of plasmid R100 and transposon Tn501: further evidence for mer genes which enhance the activity of the mercuric ion detoxification system. Molecular and General Genetics 202, 143-151.
Chandler, P. M. \& Krishnapillai, V. (1974). Isolation and properties of recombination deficient mutants of Pseudomonas aeruginosa. Mutation Research 23, 15-23.

de la Cruz, F. \& Grinsted, J. (1982). Genetic and molecular characterization of $\mathrm{Tn} 21$, a multiple resistance transposon from R100.1. Journal of Bacteriology 151, 222-228.

Diver, W. P., Grinsted, J., Fritzinger, D. C., BROWN, N. L., ALTENBUCHNER, J., ROGOWSKy, P. \& SchmitT, R. (1983). DNA sequences of and complementation by the tnpR genes of $\operatorname{Tn} 21, \mathrm{Tn} 501$ and Tn1721. Molecular and General Genetics 191, 189-193.

Finnegan, J. \& Sherratt, D. (1982). Plasmid ColEl conjugal mobility: the nature of bom, a region required in cis for transfer. Molecular and General Genetics 185, 344-351.

Fong, S. T. \& STANisich, V. A. (1989). Location and characterization of two functions on RP1 that inhibit the fertility of the IncW plasmid R388. Journal of General Microbiology 135, 499-502.

FOSTER, T. J. (1987). The genetics and biochemistry of mercury resistance. CRC Critical Reviews in Microbiology 15, 117-140.

Friello, D. A. \& Chakrabarty, A. M. (1980). Transposable mercury resistance in Pseudomonas putida. In Plasmids and Transposons: Environmental Effects and Maintenance Mechanisms, pp. 249-259. Edited by C. Stuttard \& K. R. Rozee. New York: Academic Press.

Gilbert, M. P. \& Summers, A. O. (1988). The distribution and divergence of DNA sequences related to the $\operatorname{Tn} 21$ and $\mathrm{Tn} 501$ mer operons. Plasmid 20, 127-136. 
Gringauz, E., Orle, K. A., Waddell, C. S. \& Craig, N. L. (1988). Recognition of Escherichia coli att $\operatorname{Tn} 7$ by transposon Tn7: lack of specific sequence requirements at the point of $\operatorname{Tn} 7$ insertion. Journal of Bacteriology 170, 2832-2840.

Grinsted, J., Saunders, J. R., Ingram, L. C., Sykes, R. B. \& Richmond, M. H. (1972). Properties of an R factor which originated in Pseudomonas aeruginosa 1822. Journal of Bacteriology 110, 529-537.

Grinsted, J., BenNetT, P. M., Higginson, S. \& RichMOND, M. H. (1978). Regional preference of insertion of Tn501 and Tn802 into RPl and its derivatives. Molecular and General Genetics 166, 313-320.

JobanPuTRA, R. S. \& DATTA, N. (1974). Trimethoprim $\mathrm{R}$ factors in enterobacteria from clinical specimens. Journal of Medical Microbiology 7, 169-177.

LETT, M.-C., BENNETT, P. M. \& VIDON, D. J.-M. (1985). Characterization of Tn3926, a new mercuryresistance transposon from Yersinia enterocolitica. Gene 40, 79-91.

Lund, P. A., Ford, S. J. \& Brown, N. L. (1986). Transpositional regulation of the mercury-resistance genes of transposon Tn501. Journal of General Microbiology 132, 465-480.

Maniatis, T., Fritsch, E. F. \& Sambrook, J. (1982). Molecular Cloning: a Laboratory Manual. Cold Spring Harbor, NY: Cold Spring Harbor Laboratory.

Misra, T. K., Brown, N. L., Fritzinger, D. C., Pridmore, R. D., Barnes, W. M., Haberstroh, L. \& SILVER, S. (1984). Mercuric ion-resistance operon of plasmid R100 and transposon Tn501: the beginning of the operon including the regulatory region and the first two structural genes. Proceedings of the National Academy of Sciences of the United States of America 81, 5975-5979.

RADFORD, A. J. (1984). Transposable resistance to mercuric ions and organomercurials in soil bacteria. $\mathrm{PhD}$ thesis, La Trobe University, Australia.

RADFord, A. J., Oliver, J., Kelly, W. J. \& ReANNey, D. C. (1981). Translocatable resistance to mercuric and phenylmercuric ions in soil bacteria. Journal of Bacteriology 147, 1110-1112.
Saint-Girons, I., Fritz, H.-J., Shaw, C., Tillmann, E. \& STARLINGER, P. (1981). Integration specificity of an artificial kanamycin transposon constructed by the in vitro insertion of an internal Tn 5 fragment into IS2. Molecular and General Genetics 183, 45-50.

SANChEZ, J., BENNETT, P. M. \& RichMOND, M. H. (1982). Expression of elt $B$, the gene encoding the B sub-unit of the heat-labile enterotoxin of Escherichia coli, when cloned in pACYC184. FEMS Microbiology Letters 14, 1-5.

SILVER, S. (1983). Bacterial interactions with mineral cations and anions: good ions and bad. In Biomineralization and Biological Metal Accumulation, pp. 439-457. Edited by P. Westbroek \& E. W. de Jong. Dordrecht: D. Reidel Publishing.

Sinclair, M. I. \& Holloway, B. W. (1982). A chromosomally located transposon in Pseudomonas aeruginosa. Journal of Bacteriology 151, 569-579.

Stanisich, V. A. \& BenNeTt, P. M. (1976). Isolation and characterisation of deletion mutants involving the transfer genes of P-group plasmids in Pseudomonas aeruginosa. Molecular and General Genetics 149, 211-216.

Stanisich, V. A. \& Ortiz, J. M. (1976). Similarities between plasmids of the P-incompatibility group derived from different bacterial genera. Journal of General Microbiology 94, 281-289.

Stanisich, V. A., BENNETt, P. M. \& Richmond, M. H. (1977). Characterisation of a translocation unit encoding resistance to mercuric ions that occurs on a non-conjugative plasmid in Pseudomonas aeruginosa. Journal of Bacteriology 129, 1227-1233.

Tanaka, M., Yamamoto, T. \& Sawai, T. (1983). Evolution of complex resistance transposons from an ancestral mercury transposon. Journal of Bacteriology 153, 1432-1438.

Thomas, C. M. \& SMITH, C. A. (1987). Incompatibility group $\mathrm{P}$ plasmids: genetics, evolution and use in genetic manipulation. Annual Review of Microbiology 41, 77-101.

Wallace, L. J., Ward, J. M. \& Richmond, M. H. (1981). The location of sequences of $\operatorname{TnA}$ required for the establishment of transposition immunity. Molecular and General Genetics 184, 80-86. 